company must compete are enormous organisations controlling almost unlimited resources, and if after the war these organisations continue to work with the same efficiency as before, some years must elapse before we could compete successfully with them. Failure to develop on research lines is scarcely conceivable if the works are in the hands of a highly trained chemical staff; but if the new industries get into the power of the business man who wants an immediate return for his outlay and fails to appreciate the vital importance of scientific control, then no protection by a tariff on the import of German dyes and other organic products can avert disaster.

\section{THE CO-OPERATION OF SCIENCE AND INDUSTRY.}

A DISCUSSION upon the above subject took place A. at a conference held under the auspices of the Institute of Industry and Science at the Mansion House on March 25. The chairman, Mr. Frank Warner (president of the Silk Association), in opening the proceedings, dealt with the crying need for a greater application of science to industrial problems and for the need of the organisation of industry. The two main objects of the Institute of Industry and Science he defined as the organisation of capital for industrial purposes, and the bringing about of those working conditions in which science and industry are in closer contact.

Mr. Taylor Peddie, chairman of the Institute, stated that the Institute aimed at embracing within its membership the trade organisations of the country, and that already much progress had been made in this direction and with the formation of a trade bank. Prominent men of science had joined the court of directors of the Institute, and by development of this scheme it was hoped to bring science into intimate contact with industry. Mr. Peddie then opened the discussion by reading a paper upon "The Influence of Science upon Political Economy," in the course of which he demonstrated from comparative statistics the large reductions in the cost of production that had been brought about by the application of science to processes of manufacture.

Sir Philip Magnus stated that the output of research work from the English universities was equal to that of Germany, and that their graduates were as capable and as well trained as those from the German universities; but that, owing to our lack of appreciation of science, we made practically no use of our research work, nor of our trained men. He felt that any movement trying to bring about a more marked sympathy between science and industry was worthy of the greatest support.

The Earl of Portsmouth, in moving a resolution to the effect that the meeting supported the organisation of capital for industrial purposes, and that it agreed that a closer co-operation of science and industry was essential, stated that he was of opinion that in the near future the people now drawing their income from land and property would by force of circumstances be compelled to turn their attention to industrial affairs.

The Hon. F. Mackenzie (Agent-General for New Zealand), in seconding the resolution, expressed the opinion that we were too prosperous in this country to appreciate the need for organisation. He stated that twenty-five years ago agriculture in New Zealand was at a very low ebb, farmers were selling sheep at the rate of $18 s$. $9 d$. a gross, butter was $4 d$. a $1 \mathrm{~b}$., but now, through careful organisation and the application of science to agriculture, New Zealand was. a prosperous country, exporting a considerable amount of produce to England.

S. R. I.

\section{THE INSTITUTION OF NAVAL ARCHITECTS.}

THE spring meetings of the Institution of Naval Architects opened on .Wednesday, March 24. Owing to the war, the meetings were curtailed somewhat; eleven papers were read and discussed at morning and afternoon meetings on. Wednesday and Thursday. The Marquis of Bristol was re-elected president for the ensuing year, and in his opening address made reference to Germany's methods of submarine war. He suggested that, in order to obtain reasonable protection from submarine attack, it might be advisable to arm all merchant vessels to an extent which would render them dangerous to submarines.

Prof. J. J. Welch's paper on the watertight subdivision of ships was limited to a discussion of the orderly subdivision of ships, particularly as effected by transverse watertight bulkheads. The paper included a historical sketch leading up to the work of the bulkhead committee of I9I2. One of the difficulties which had to be faced by this committee was the question of permeability. The same ship, whilst loaded to the same water-line, might carry cargo of very different density, so that with the same arrangement of bulkheads different standards of safety would obtain on the two voyages. Ultimately the conclusion was reached that a fair average permeability for cargo spaces was 60 per cent. Spaces devoted to passengers are taken at 95 per cent. permeability, and machinery spaces at 80 per cent. The paper goes on to discuss the recommendations of the bulkhead committee's report on oversea passenger vessels, and the author considers that the proposals in the report represent a very decided step forward.

An interesting paper on the influence of discharging appliances on the design of large ore carriers was read by Mr. John Reid. The shipment of ore on the Lakes Superior and Erie route has reached in one year the enormous total of nearly $50,000,000$ tons. The author gives a description of the Hulett unloading machine, an appliance which has enabled a cargo of Io,000 tons of ore to be unloaded on the Great Lakes in less than three hours. Unloading and loading machinery of this description has led to the design of ore-carrying steamers in which the greater part of the length of the vessel is taken up with cargo holds; and practically the whole deck is covered with hatches. The rapid loading of such vessels is apt to produce great strains; a speaker in the discussion instanced a case of one of these vessels acquiring a deflection of $1 \times \frac{1}{2}$ in. during loading. The author of the paper directed attention to the backward state of the facilities in Great Britain for handling and transporting ore, and showed how some of the leading features of the Great Lake ore-carriers may be adapted with advantage for ocean-going ore-carriers.

Mr. J. Montgomerie read a paper on the scantlings of light superstructures, by which is meant the light steel deckhouse erections now commonly fitted above the strength deck in passenger steamers. Two alternatives present themselves to the designer:-(I) The structure may be made so flexible that it cannot take any share in the straining action to which the vessel is exposed as a whole; (2) it may be made strong and rigid enough to share that general straining action without damage. The first method of design is impracticable, since the superstructures have to carry heavy weights such as boats, casings, and funnels, and the structure has to be substantial enough to support these when the ship is moving in a seaway. Partial fiexibility may be obtained by cutting the superstructure at several places and fitting expansion joints. The whole efficiency of such joints, in respect of the relief from stress which they afford to a long house,

$$
\text { NO. 2370, VOL. 95] }
$$


depends on the distance between them, and that in turn states a problem in shipbuilding which has never been solved satisfactorily, viz., the determination of the distribution of stress in way of an abrupt discontinuity, such as a bridge, or other erection. In the absence of any theory to which complete assent can be given, we must turn to the record of experience. The author then proceeds to give descriptions and illustrative sketches showing typical cases of damage to existing ships at places of discontinuity. These examples are of particular value to engineers and others interested in the strength of materials, and will well repay careful study.

An analysis of the damage observed supports certain conclusions which can be drawn from a consideration of the whole question of superstructures:-(I) That in way of a discontinuity in the structure of a ship, stresses outside the erection will be transmitted to the material of the deeper girder much more rapidly than has been thought to be the case; (2) that the fitting of expansion joints, spaced as in the present practice, does not appreciably relieve the superstructures of stress, or obviate damage; (3) the best method of providing against damage in deckhouse superstructures is to dispose the material so as to make these capable of taking part in the straining action of the hull, following as far as possible the general law that all discontinuity of longitudinal material should be minimised. The author then proceeds to take certain typical cases, and gives methods of working out the scantlings required to comply with $(3)$, above noted.

$\mathrm{Mr}$. F. W. Lanchester gave a contribution to the theory of propulsion and the screw propeller. The author made reference to the controversy in which Dr. Froude's work was attacked violently by Prof. Henderson. Without entering, or taking part, in the dispute, Mr. Lanchester reviews the theory from its foundation, in order to make sure of his own ground. In the past there appears to have been insufficient attention to the initial definition of the problem, with corresponding uncertainty as to the ultimate interpretation of results. In discussing Dr. Froude's theory, and speaking academically, Mr. Lanchester says that the weak point of the whole conception is that there is no proof offered that either the work done (i.e. the energy expended), or the momentum communicated, is confined strictly to the column of fluid passing through the actuator, and there is, in fact, nothing to restrict, or confine, the fluid as in the case of the efflux theory, by which the problem is rendered really definite. It is understood that the régime contemplated by Dr. Froude is not capable of exact expression. This, however, is no obstacle to the application of any theory in real hydrodynamics; if it were necessary for the engineer to await the work of the pure mathematician in these matters, the subject would have made scarcely perceptible progress since the time of Noah. In such a case as the present, if the method of treatment contains 80 or 90 per cent. of truth, it may demand acceptance.

Further work at the William Froude National Tank on the resistance of mercantile ship forms was presented by Mr. J. L. Kent, and Mr. Stromeyer contributed an interesting paper on the law of fatigue applied to crankshaft failures.

\section{EAR PROTECTION AGAINST ARTILLERY SOUNDS.}

THOSE who have associated with our gunners must have noticed how often they suffer from deafness. The sudden access of pressure in the neighbourhood of a gun at the moment of firing imposes so great a strain on the drum of the ear that deafness is a usual result. The increase in pressure in the NO. 2370 , VOL. 95] modern gun, and the high pressure still remaining when the shot reaches the muzzle, make the conditions more serious than they used to be comparatively recently. Not only those who are near the gun when fired, but those also in the neighbourhood of bursting shells, bombs, or explosives, are liable to suffer in a similar way even if they are not otherwise damaged.

Mr. A. Mallock, F.R.S., who has for many years conducted investigations in connection with artillery, has invented an "ear defender," the object of which is to protect the drum of the ear from very sudden and violent access of pressure, while still allowing the minute variations produced by ordinary sounds to be received with but little loss. The defender consists of a containing piece made of ebonite and shaped like the pieces used in the game of Halma, and of about the same size. The ball end is very finely milled, and it is made to fit the passage of the ear, there being five sizes, differing very slightly in size in this part, to suit different people. The piece is pierced centrally by a hole $5 \mathrm{~mm}$. in diameter at the small end, and gradually enlarging towards the other end, where it opens into a recess $\mathrm{I} \mathrm{cm}$. in diameter. Into this are fitted in order a flat ring washer, a disc of fine wire gauze, a very thin, flat ring washer, a delicate diaphragm, a very thin, flat ring washer, a disc of fine wire gauze, and a flat ring washer. When a pair of defenders are placed in the ears, the thin diaphragms, untouched except near their edges, where they are held, are free to take up aerial vibration and to transmit it to the ear passage, and so the wearer hears ordinary sounds with but little loss; when, however, the violent impact due to gun fire or explosion in the neighbourhood occurs, the diaphragm is brought up against the wire gauze, by which it is prevented from further movement, thus limiting the increase of pressure in the air passage and defending the ear.

The defenders are neatly packed in a small tin matchbox with a rubber fitting, which prevents them from falling out, but which allows them to be removed at once. A small cleaning tool is similarly held elastically so that it cannot fall out by accident. The price of the set is three shillings, and at the present time there is great scope for its use. The instrument is called the Mallock-Armstrong ear defender, and the address of the proprietors is 86 York Street, Westminster.

C. V. B.

\section{SOME SCIENTIFIC ASPECTS OF PIANO-PLA YERS. 1}

THERE are few modern inventions which have not been employed in the present war for the destruction of property and of human life. The pneumatic piano-player is an exception. It is also exceptional in that it possesses but a scanty literature outside the catalogues of the manufacturers. It has never been associated with any inventor of distinction, and the general public knows nothing about its history. The aeroplane, on the other hand, is closely linked in popular thought, not only with such modern names as Wright, Langley, and Blériot, but also with the names of early designers and, projectors of flying machines, such as Dante of Perugia and Leonardo da Vinci. Yet, considered merely from an engineering point of view, the modern piano-player is a marvel of human ingenuity.

The feature which distinguishes it from its early predecessors is the element of controllability, which leaves the interpretation of the music largely to the

1 Abridged from a discourse delivered at the Royal Institution on Friday, March 19, by Prof. G. H. Bryan, F.R.S. 